\title{
MAIN FEATURES OF A 3D GIS FOR A MONUMENTAL COMPLEX WITH AN HISTORICAL-CULTURAL RELEVANCE
}

\author{
A. Scianna ${ }^{\text {a }}$ M. La Guardia ${ }^{\text {b }}$ \\ a ICAR-CNR (High Performance Computing and Networking Institute - National Research Council of Italy) at GISLab c/o D'Arch, \\ Polytechnic School of University of Palermo, Viale delle Scienze, Edificio 8, 90128 Palermo, Italy \\ andrea.scianna@cnr.it \\ ${ }^{\text {b }}$ DIID, at GISLab c/o D'Arch, Polytechnic School of University of Palermo, Viale delle Scienze, Edificio 8, 90128 Palermo, Italy \\ marcellolaguardia87@libero.it
}

KEY WORDS: 3D model, 3D GIS, Cultural Heritage, BIM technologies

\begin{abstract}
:
The last achievements of technologies in geomatics especially in survey and restitution of 3D models (UAV/drones and laser scanner technologies) generated new procedures and higher standards of quality in representation of archaeological sites. Together with Geomatics, the recent development of Information and Communication Technologies (ICT) strongly contribute to document and the Cultural Heritage $(\mathrm{CH})$. The representation and documentation of $\mathrm{CH}$ using these new technologies has became necessary in order to satisfy different needs: - for restorers in order to acquire a deep knowledge of the cultural good and to define possible strategies of restoration; - for the conservation of information, allowing to preserve the 3D geometry of the monumental complex with the integration of descriptions about architectural elements; - for touristic aims, giving the opportunity of sharing $\mathrm{CH}$ information on web, allowing users to visit and explore, in a virtual way, monumental complexes, acquiring information details about architectural elements or the history of monumental complex.

Looking through these new scenarios, the development of a 3D Geographic Information System (GIS) applied to a cultural good could be, today, an added value of fundamental importance for full description and data management of monumental complexes.

In this work, the main features necessary for the correct construction of a 3D GIS of a monumental complex will be analyzed, with a particular focus on the possibilities for creating a standardized procedure to follow.
\end{abstract}

\section{INTRODUCTION}

During these last years UAV/drones technologies became more powerful, allowing the generation of detailed point clouds from photogrammetric restitutions of high resolution images (Siebert, Teizer, 2014). On the other hand, laser scanner technologies have evolved a lot in these last years, making available instrument more compact and at the same time more powerful, with even more accurate acquisition capabilities in a shorter working time (Fabbri et al, 2016). Anyway, these capabilities of big data acquisition should be accompanied by detailed semantic descriptions, in order to be exploited in the best way for creating a full 3D model of monumental complexes (Scianna et al., 2016; Dore et Murphy, 2012).

Besides, the implementation of Geographical Information System (GIS) technologies applied to archaeological remains has achieved fundamental importance on valorization of $\mathrm{CH}$ for touristic aims, and it could be an important step for planning its restoration (Pelcer-Vujacic and Kovacevic, 2016).

Furthermore, in archaeology, the integration of semantic data with $\mathrm{CH} 3 \mathrm{D}$ models using BIM technologies (Scianna et al. 2014) allows to preserve an exhaustive level of information of the cultural good available for all stakeholders. Therefore, the use of Information and Communication Technologies (ICT) for documentation of $\mathrm{CH}$ became more and more diffused; in particular, the development of 3D GIS technologies applied to $\mathrm{CH}$ has a fundamental importance for sharing information about the cultural good in a more comprehensible form. Especially for monumental complexes organized on more levels, the use of a classic 2D GIS ( with points, lines or polygons) for describing rooms, walls and ruins, it is not enough (Marques et al., 2017). In this case the presence of the third dimension on the representation is fundamental, in order to identify and separate overlapping bi-dimensional elements. Besides, the use of a 3D GIS for representation of $\mathrm{CH}$ models, with the possibility of query on 3D elements, makes the acquisition of knowledge more immediate in an user-friendly way also for not specialized users (e.g. tourists).

The construction of a 3D GIS $\mathrm{CH}$ model requires a detailed planning operation, because the 3D model should be strongly linked with the LoD (level of detail) of information of the database associated to it. For this reason the preliminary study of the archaeological site, carrying out also a deep investigation about the main architectural features, is a necessary step for the next creation of the database structure (Scianna et al. 2004).

\section{THE IMPORTANCE OF 3D GIS FOR THE REPRESENTATION AND DOCUMENTATION OF CH}

The necessity of using ICT technologies for the construction of $\mathrm{CH}$ 3D GIS is growing more and more in recent years. In fact, these technologies allow to satisfy different needs regarding the $\mathrm{CH}$.

In particular ICT technologies are very useful for restoration, conservation and fruition of cultural goods.

For restorers, first elements of an historical building to be considered, are its structure, and the disposition on interiors, necessary to choose the correct operations. For this reason, the possibility of navigating inside the 3D model is important for acquiring a deep knowledge of the object.

Strongly linked to the restoration is the problem of the conservation of information. In fact sometimes natural events (heartquakes, storms, etc.) or human destructive actions (wars, terrorism, etc.) could irreversibly damage monuments, museums 
or archaeological sites. The construction of a 3D GIS allows to preserve information about the 3D geometry of $\mathrm{CH}$ and its related semantic description saving information for subsequent needs.

During these last years the navigation inside 3D environment has been even more usual among users especially for the young generation. For this reason the opportunity of sharing $\mathrm{CH}$ information on web, where everyone could navigate and explore $3 \mathrm{D} \mathrm{CH}$ models in an interactive way, consists in a fundamental opportunity for touristic aims.

Analyzing what said before it's possible to assert that the definition of the main features of a 3D GIS applied to $\mathrm{CH}$ is necessary for multidisciplinary needs.

The importance of using ICT (Information and Communication Technologies)

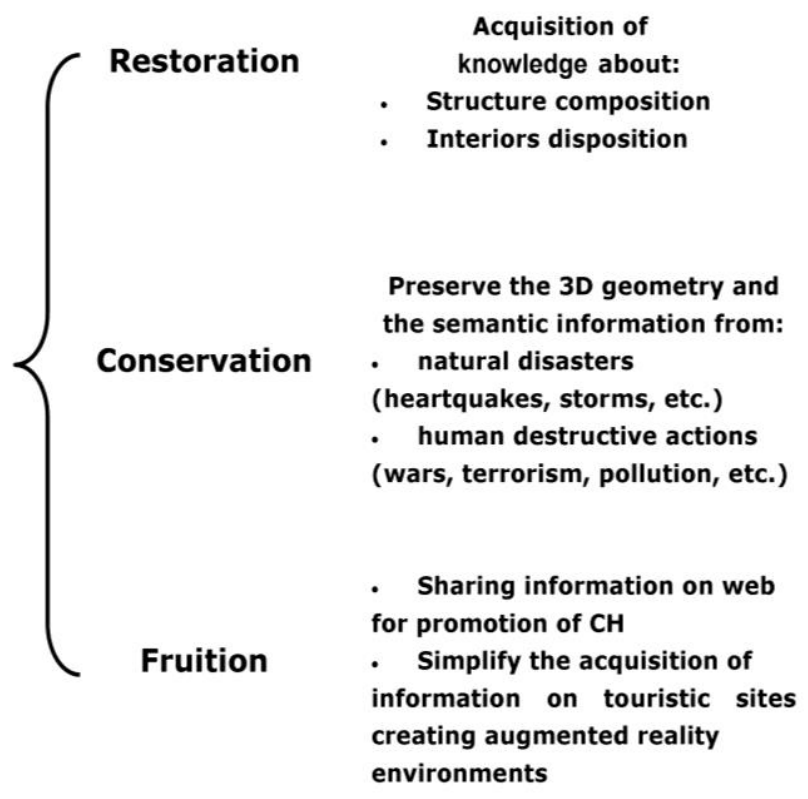

Figure 1. The contributes if ICT technologies.

\section{THE CONSTRUCTION OF A 3D GIS}

The structure of a 3D GIS consists of 2 fundamental parts: the geometric 3D model and the database associated to it. This structure allows to connect the $3 \mathrm{D}$ visualization of the archaeological area to an external database, in order to link the geometric 3D elements of the model with their corresponding table of attributes, which contains the semantic description.

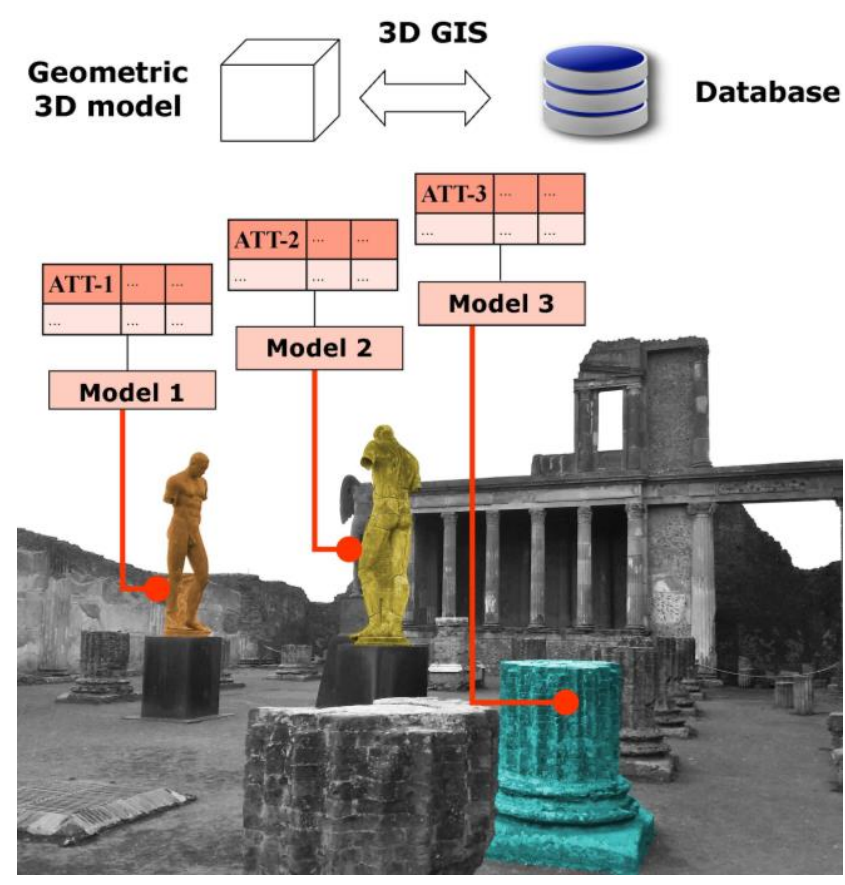

Figure 2. An example of a structure of a 3D GIS (Pompei ruins).

Semantic data consists of :

- Information on building materials

- History of construction phases

- Modification applied during restoration phases

- Type of material used in the different stage of restoration for each building element

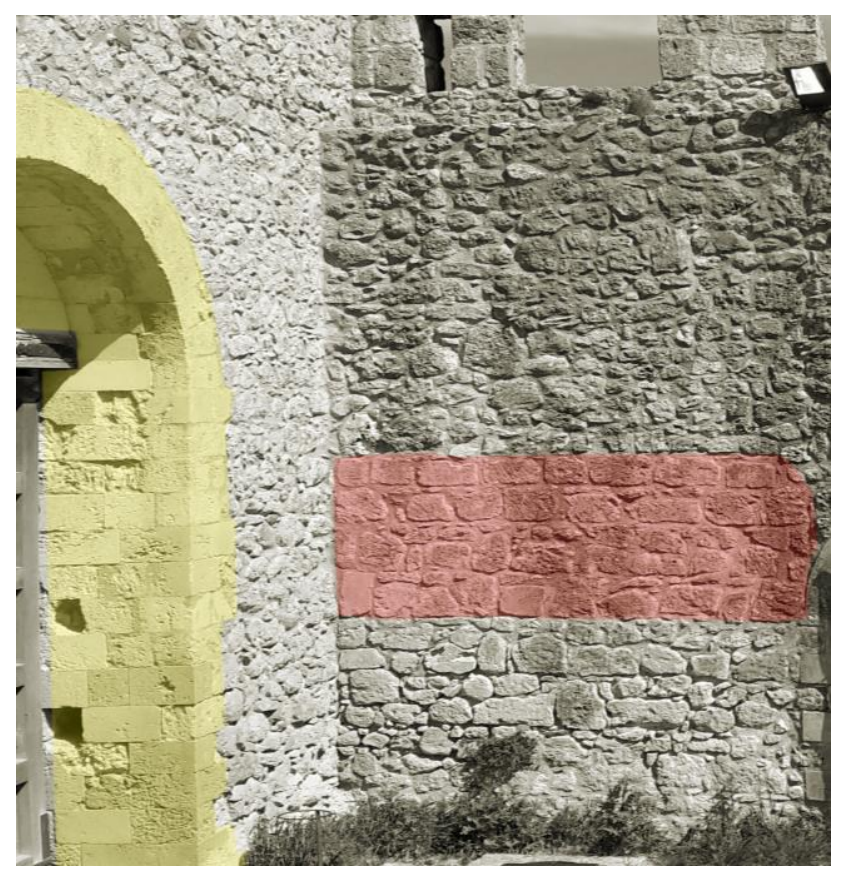

Figure 3. The medieval courtyard of the castle of Mussomeli with different materials used on different stages of restoration (in red and in yellow). 


\subsection{Definition of the conceptual model}

Before any operation, the construction of the conceptual scheme is the first step for the creation of a 3D GIS, in order to:

- Identify classes of data to acquire both for geometry and semantics (attributes)

- determine the necessary LoD for the restitution of survey, in relationship with the related scale of the elements to describe in the database.

During this step it's necessary to acquire a deep knowledge about the cultural good to represent, focusing the attention on categorizing spaces (areas of main interest) in order to describe them at right LoD according to different base needs for 3D GIS construction.

\section{CONCEPTUAL SCHEME}

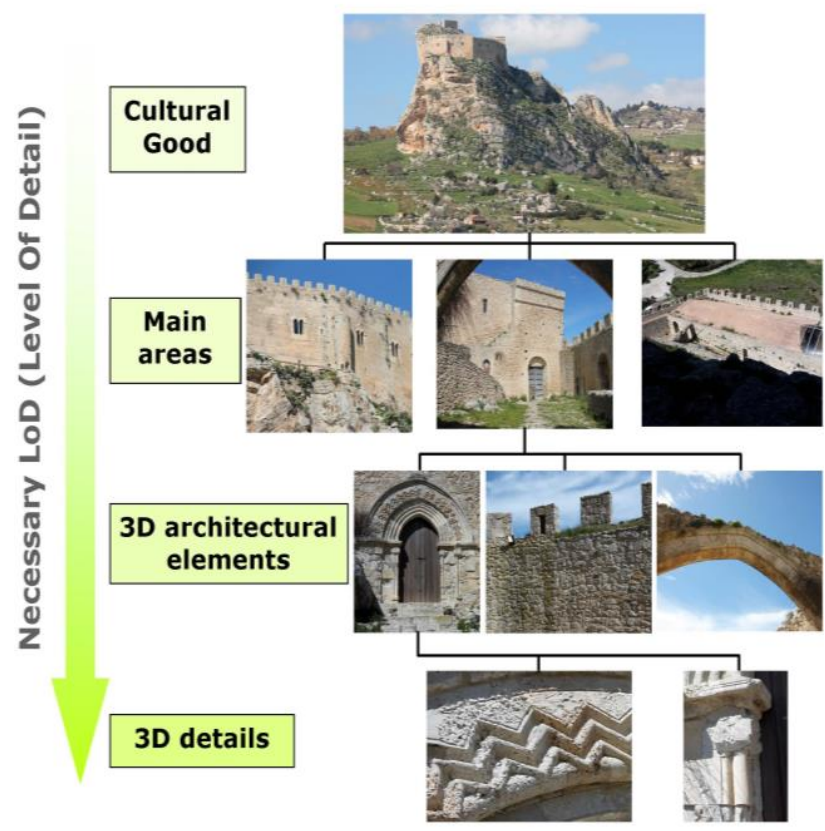

Figure 4. The different LoD on the multiscale model of the castle of Mussomeli.

Besides the identification of the areas of building, the decomposition of building structure of the cultural good is a fundamental step for the construction of the conceptual schema of the database and subsequent logic and physical models (Scianna et al., 2014). This operation is also typical for the BIM (Building Information Modeling) 3D model representation; unlike BIM (based on a standard like Industry Foundation Classes), for cultural heritage a standardized decomposition model internationally recognized doesn't exist. In some countries exist national standard proposals like Italian ICCD (Istituto Centrale per il Catalogo e la Documentazione dei beni culturali) model that should be adapted to modern ways to create catalogs for $\mathrm{CH}$ (from paper descriptive sheets to alphanumeric-graphic geospatial 3D database). This model borns far in the time and is tailored for a vision of a cultural good based on sheets. Today computer science technologies allow to access data starting from browsing of the 3D model and some data like "geographical coordinate" area features owned by graphic description of building elements (represented by graphic objects).
The steps previously listed are necessary for the construction of a 3D GIS for monumental complexes, where geometric elements, or groups of them, have to be associated with semantic metadata inserted into geospatial database as attributes.

\subsection{The survey}

Once defined the conceptual scheme, the survey operation strongly depends on the required precision, necessary for the construction of the 3D model that should be geo-referenced acquiring also a set of ground control points (GCP). The choice of the correct equipment to use ( UAV technologies, GNSS receivers, Laser scanners) has a fundamental importance for the acquisition of the correct information in the form of point clouds. It depends on the features of the cultural good to represent, and the LoD required. For example, using Laser scanner and GPS receivers, generally, it's possible to obtain a more detailed and heaviest point clouds, but these, once obtained, could became hard to manage during computer processing.

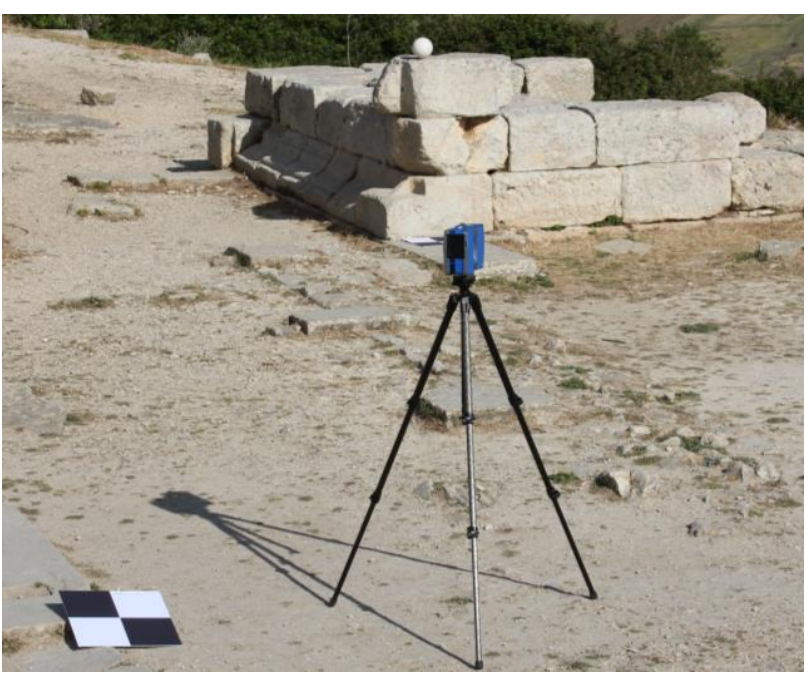

Figure 5. Laser scanner survey at theater of Segesta.

For this reason the use of a Laser scanner is recommend for limited and accessible areas or single elements ( like statues) of an archaeological site. Instead for larger sites or entire landscape restitutions, UAV technologies and GNSS receivers give the possibilities of make a photogrammetric reconstruction of large and impervious areas, with the correction given by ground control points.

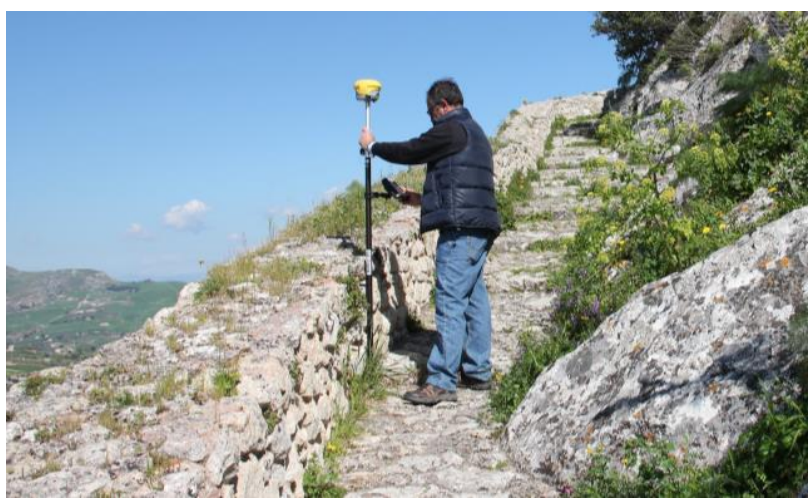

Figure 6. GCP GNSS suvey at castle of Mussomeli. 
Sometimes the collection of GNSS coordinates with a high accuracy is not allowed for different reasons (such as multipath of GNSS signal due to presence of very high walls or element like the rock in figure 6); so in order to fulfill the required precision a reference network must be build and some points have to be located using different instruments like total station. Furthermore, it's possible to obtain a detailed photogrammetric restitution of point clouds of limited areas simply using an SLR camera, taking photos on multiple positions from different angles of view.

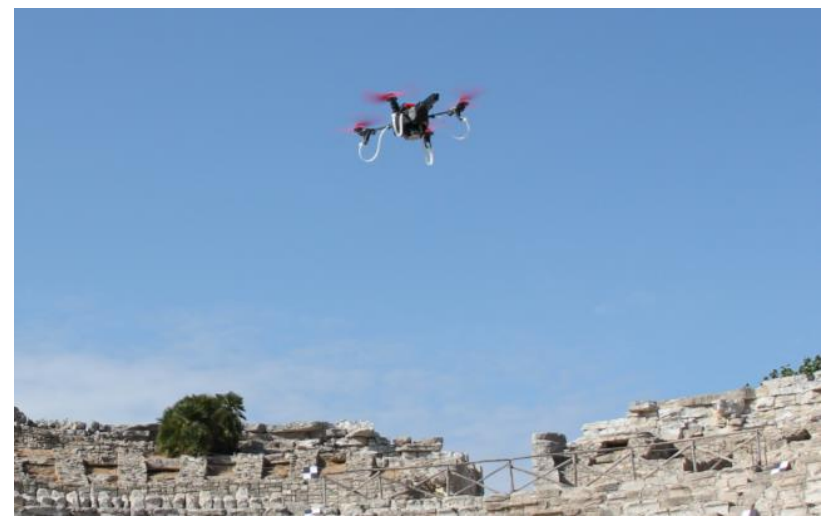

Figure 7. UAV survey at theater of Segesta.

Also for this last case it's necessary to matching the model with the reference of ground control points from a GNSS receiver. Once obtained the point clouds of the monumental complex from survey operations, the restitution processing allows to build the 3D model of the cultural good.

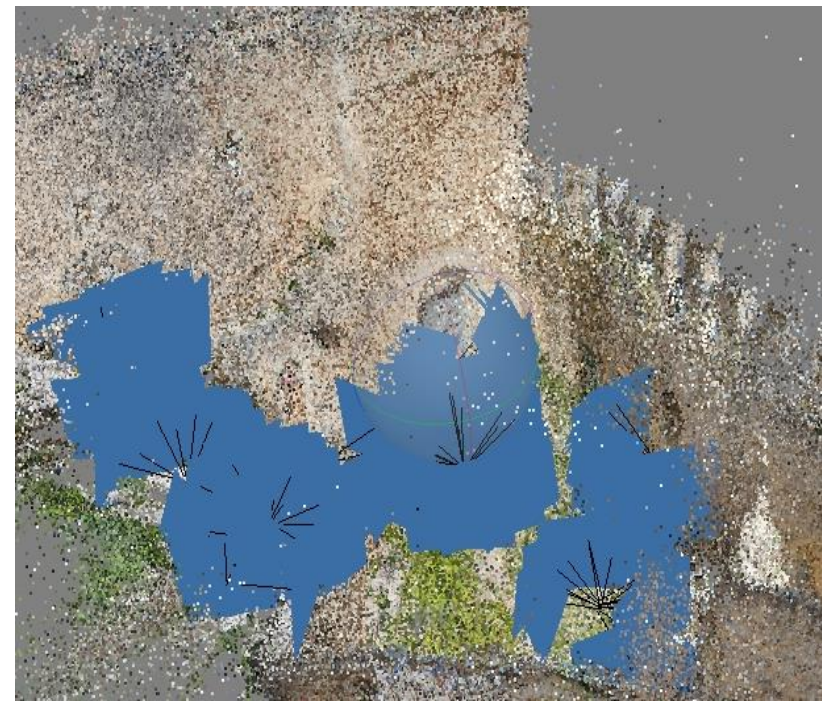

Figure 8. A restitution of a point cloud of a monumental complex generated from a photogrammetric survey.

\subsection{The construction of the 3D geometric model}

The point clouds obtained from surveys are full of clusters and usually too heavy to be instantly aligned. For this reason they must be correctly simplified and referenced using GNSS ground control points, in order to create correct and useful dense clouds. After this process all of the dense clouds have to be matched for building a complete model that covers the entire area (e.g. an archaeological area).

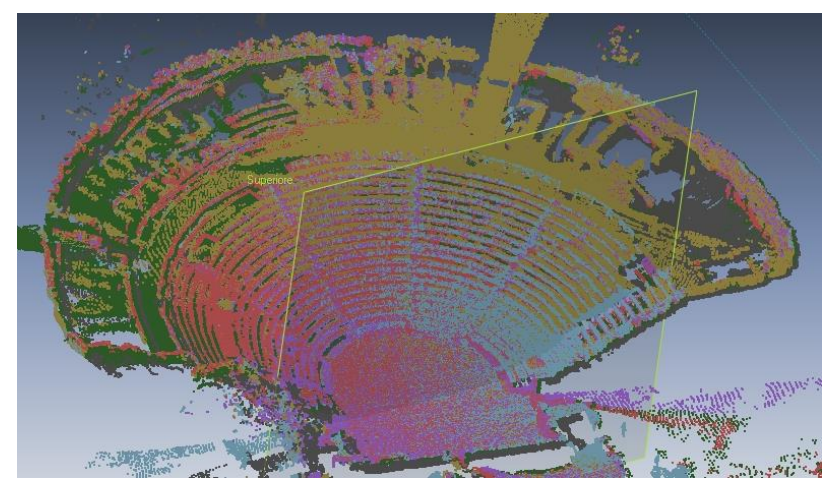

Figure 9. Matching of dense clouds (theater of Segesta)

Consequently the 3D mesh is generated from the dense cloud. This 3D entity, obtained from a combination of triangles, could be further simplified, in order to produce a lighter navigable model, ready to be imported a 3D GIS environment.

\subsection{The design of the database}

The design of the database architecture has a fundamental importance on the architecture of a 3D GIS, because the complexity and the usefulness of the information structure depends on it. Indeed the information structure of the monumental complex is divided in macro-categories, categories and subcategories of architectural elements, according with the geometric features of the represented cultural good.

Usually the structure of the database changes also as function of the architectural features, that often differ for every archaeological site. In fact, the creation of a standardized model of $\mathrm{CH}$ database is an hard final goal to reach.

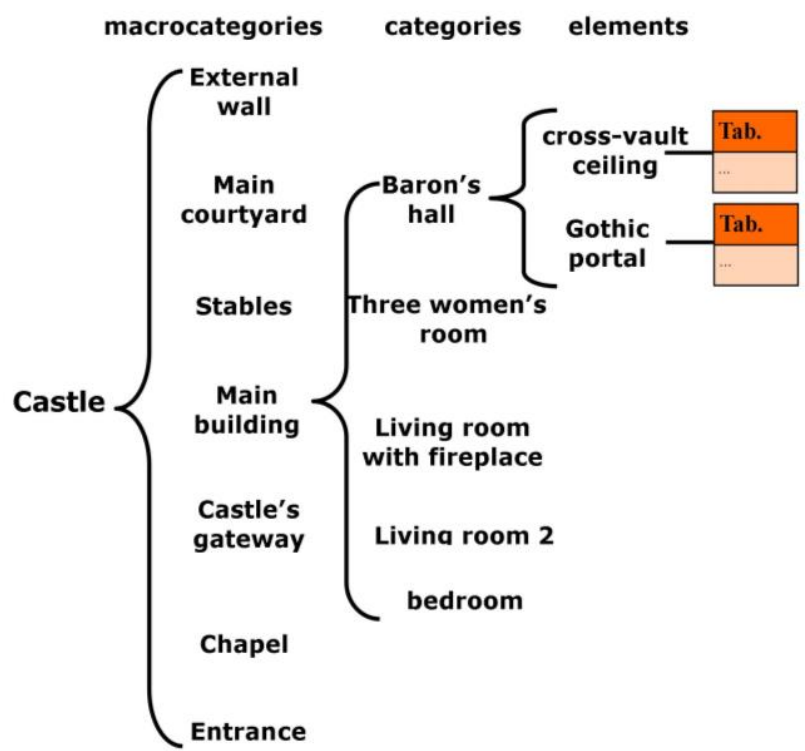

Figure 10. The schema of the database structure of the Castle of Mussomeli.

Another important parameter that characterizes the structure of the database is the achieved LoD of information. This one is also strongly connected with the complexity of the 3D geometric representation, because both of them should hold the same LoD. 
For this reason the semantic database schema and 3D model acquisition have to be planned during the conceptual scheme definition as first thing, considering the same scale definition for every level of representation. The creation of a multiscale structure is a fundamental feature for the development of a useful 3D GIS, because the implementation of different levels of scale could be useful in order to acquire a depth knowledge of the cultural complex, for multidisciplinary use. The creation of a 3D GIS of $\mathrm{CH}$ that shows different LoDs depending on the scale of visualization, is very useful for conservation, restoration and fruition of the cultural good.

\section{EXAMPLES OF 3D GIS STRUCTURES FOR CH IN SICILY}

Some last research developed at GisLAB in Palermo in occasion of European Projects (Hologramme Project, PON NEPTIS Project) focused attention on the development of 3D GIS procedures studying different kinds of cultural goods present in Sicily, that differ on archaeological and/or architectural features. For every cultural good has been planned a different operative approach, cause the differences between these studied sites.

\subsection{The case of the Theater of Segesta}

The Theater of Segesta was built between the IVth and the IIth Century B.C., and consists in one of the most important examples of theatrical architecture that holds both Greek and Roman building tradition. Now the theater is one of the most important structures of the Archaeological Park of Segesta (Trapani, Sicily), and is still in activity for theatrical events and concerts (Tusa, 1991). As first step has been studied the structure of the theater, and the main features that characterized the Greek and Roman architecture for this kind of buildings. Next has been created an hierarchy of classes, divided on micro-categories, categories and macro-categories.

Once established the max LoD to obtain, the survey campaign has been planned. For the reconstruction of the terrain around the object the use of UAV technologies has been necessary, in order to make a photogrammetric reconstruction of the Digital Elevation Model (DEM) of the entire area of the Archaeological Park of Segesta.

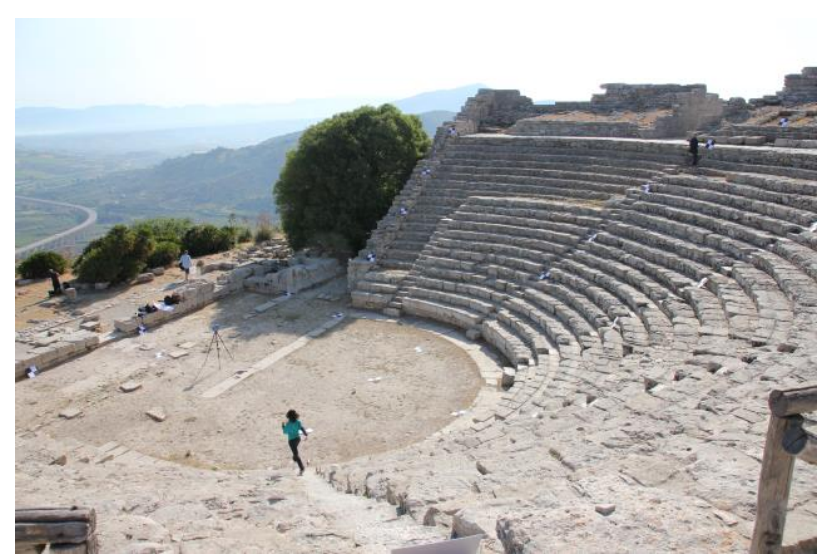

Figure 11. Surveys at the Theater of Segesta.

Instead for the reconstruction of the Theater itself has been used laser-scanner technology; the surveys have been integrated by the acquisition of a set of GNSS Ground Control Points, necessary for the correction of the obtained point clouds and their precise alignment. The model generated from the interaction of the point clouds has been strongly simplified and schematized to be easily implemented on the 3D GIS (Scianna et al. 2016).

After the construction of the 3D geometric model, the Shapefile database has been populated, in order to characterize every geometric element with the corresponding attributes.

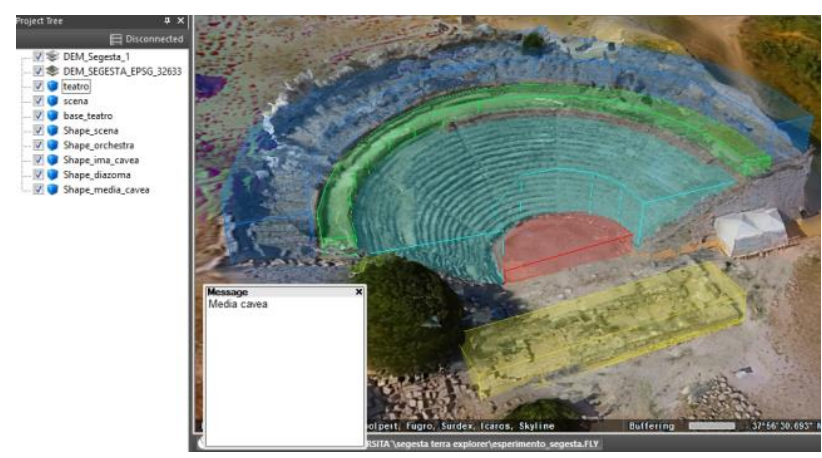

Figure 12. Decomposition of the theater of Segesta (3D features)

\subsection{The case of the Archaeological Site of Mokarta}

The Archaeological Site of Mokarta (Trapani, Sicily) is one of most ancient prehistoric proto-urban towns founded in Sicily, and was established between the late 13th and 11th Century B.C.. The village of Mokarta consists on a necropolis of about 100 tombs, with a characteristic "cave" form, linked with external space by circular dromos (passageway) (Tusa et Nicoletti, 2000; Tusa, 2009).

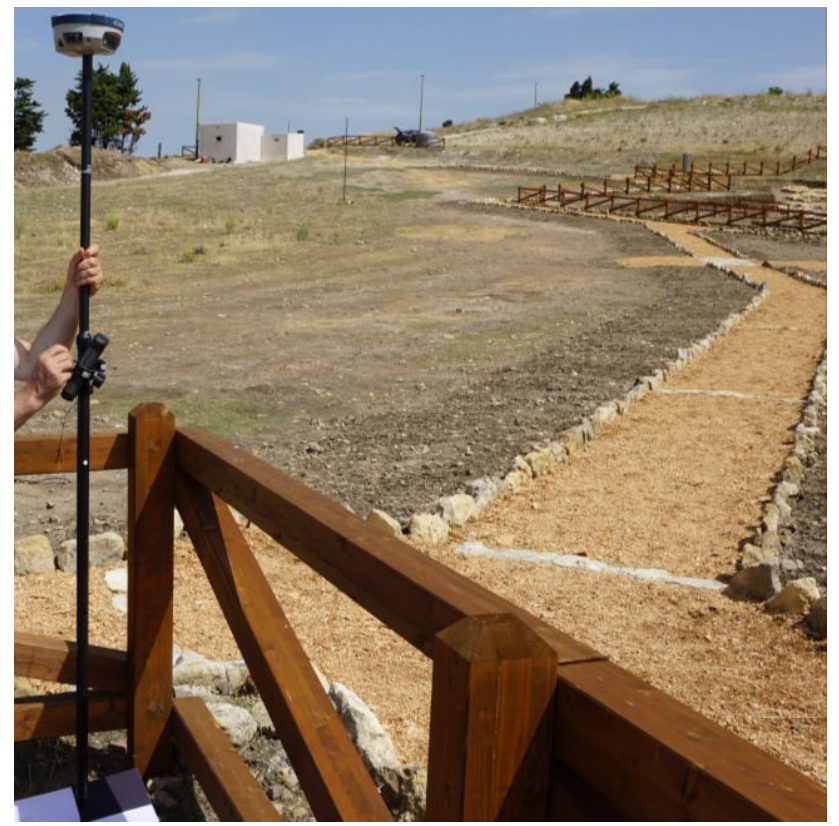

Figure 13. GCP GNSS survey at the archaeological Site of Mokarta.

This cultural good presents different features from the Theater of Segesta; first of all the archeological site consists on prehistoric ruins, and there aren't architectural volumes on the ground, but only the remained tomb's walls.

For this reason the use of laser-scanner hasn't been required, and it's been preferred UAV technologies and GNSS restitutions for the 3D geometric construction of the model (Scianna et al, 
2016). The construction of the database associated to the model considered the main huts of the archaeological site, in order to associate a semantic information to the 3D geometric representation.

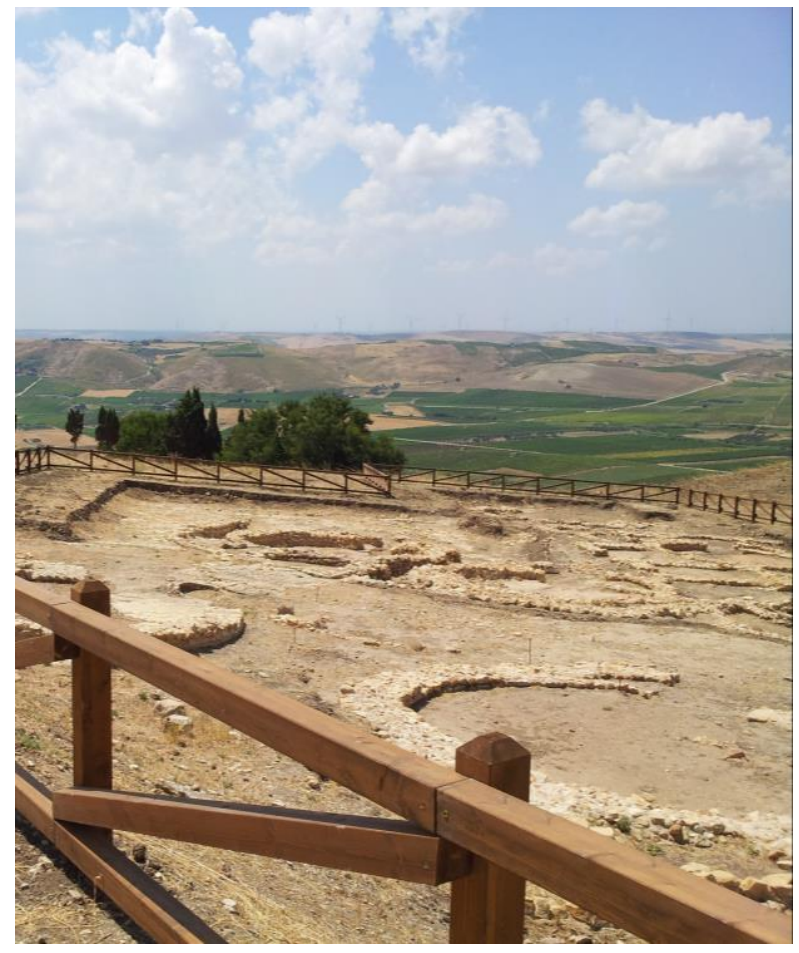

Figure 14. The ruins of the Archaeological Site of Mokarta.

The construction of this 3D GIS has been very useful for promoting the archaeological site, and sharing the knowledge about the local $\mathrm{CH}$.

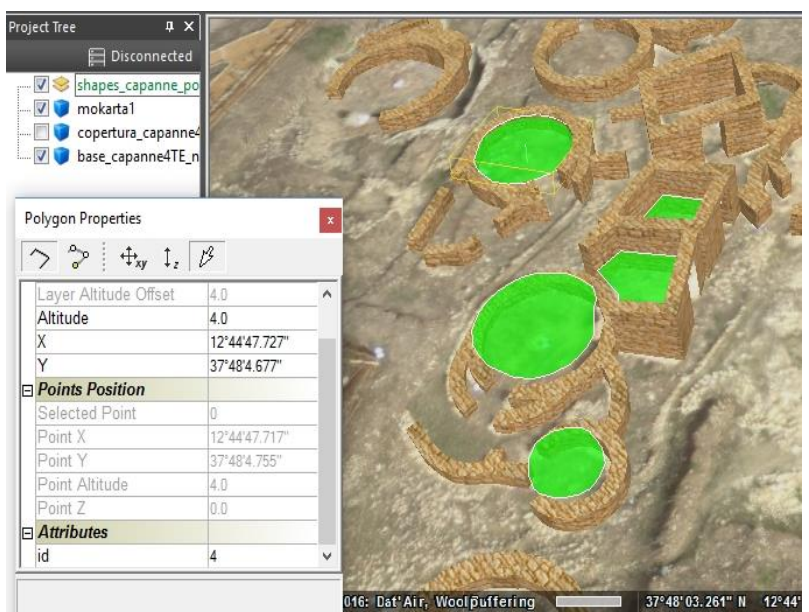

Figure 15. 3D features of the 3D GIS model of the archaeological site of Mokarta.

\subsection{The case of the Manfredonic Castle of Mussomeli}

The Manfredonic Castle of Mussomeli, located on a massive rock that dominates the town, was made in 1374 in Sicily by Manfredi Chiaramonte. It's a classic Medieval Castle with external walls (comprehensive of merlons and mullioned windows), an extended main courtyard, big rooms, tunnels, secret rooms, chapel, underground spaces.

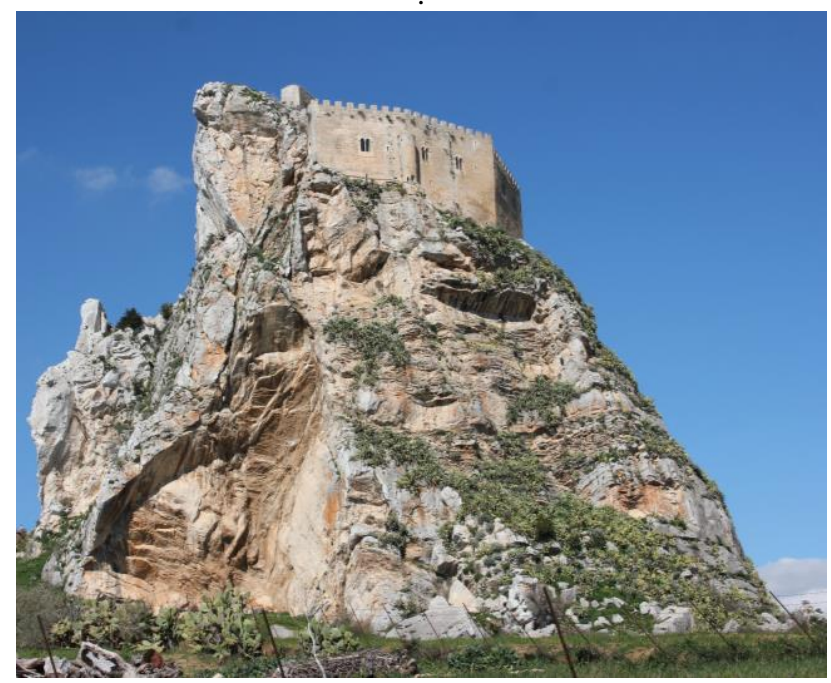

Figure 16. The Manfredonic Castle of Mussomeli.

This cultural good represents a very complicated but at the same time amazing case, cause its unique location, and cause the internal complexity of architectural distribution. For the 3D reconstruction of the castle has been necessary the survey of the entire massive rock, because every part of the castle is dislocated inside it.

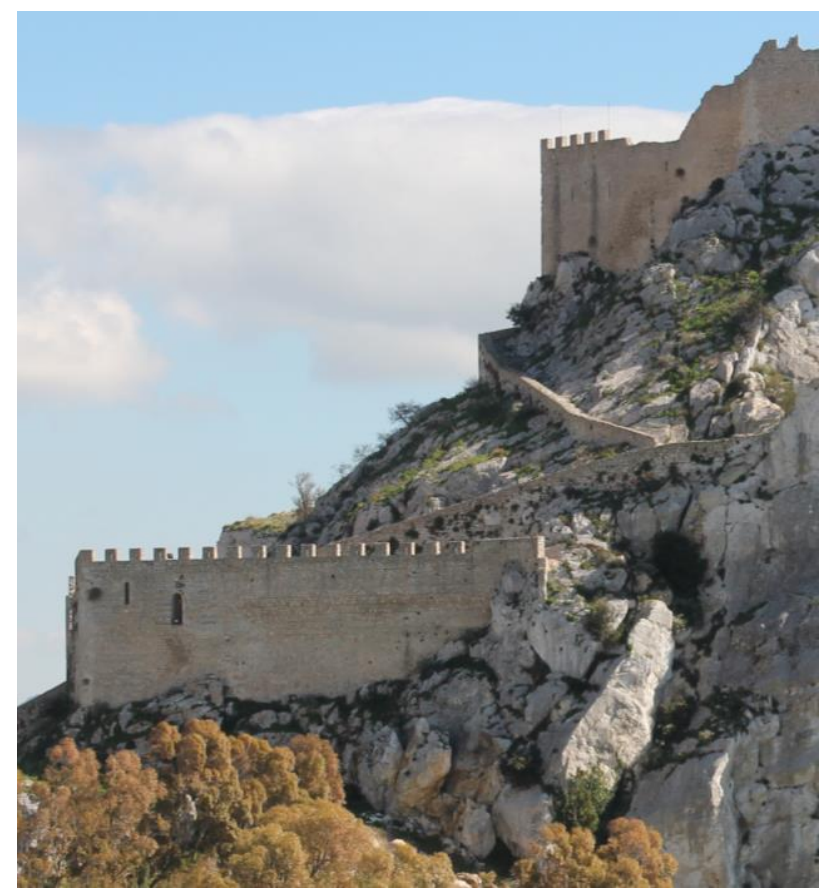

Figure 17. The impervious areas around the castle.

For the survey UAV and SLR camera technologies and GNSS surveys have been used, because almost all of external areas to reconstruct are impervious, so the only way forward has been the photogrammetric restitution.

The construction of a 3D GIS has been absolutely necessary for the correct representation of this cultural good, because its position, dislocated among the massive rock, and also the presence of many corresponding rooms in horizontal section on the main building. The castle in the database hierarchy has been 
divided into main areas (the main building, the external and internal walls, the lower block, the tower).

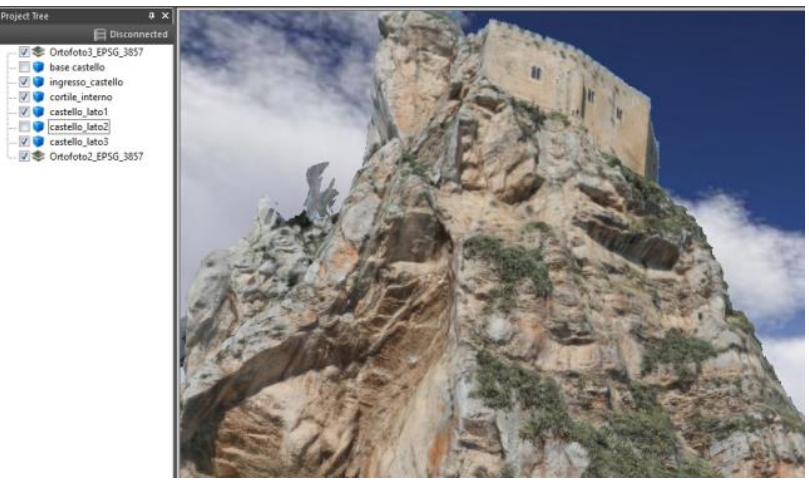

Figure 18. The 3D virtual reconstruction of the castle of Mussomeli.

Every area has been divided into categories, that consist into the main environments, like halls, rooms, courtyard etc. Inside these environments are located the architectural elements, like portals, vaults, merlons, mullioned windows, etc.

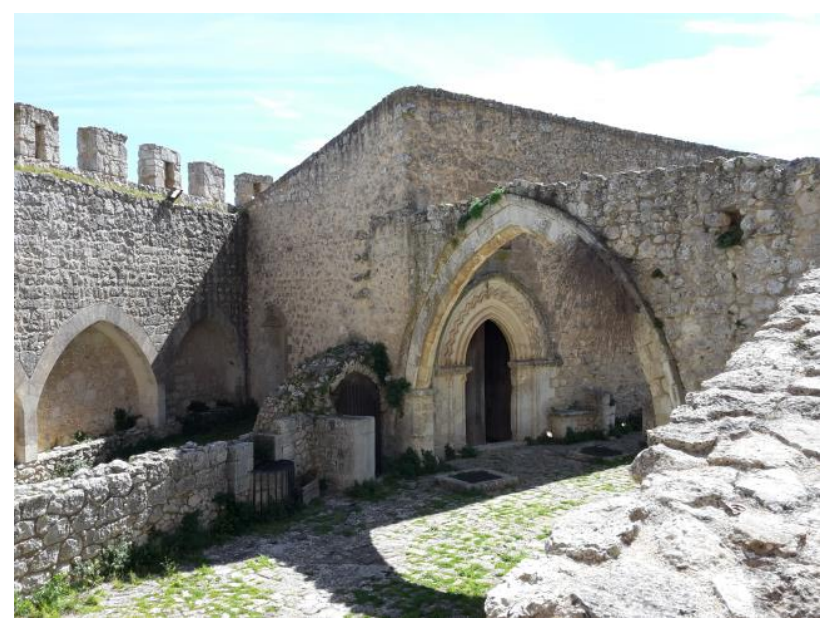

Figure 19. The main courtyard of the castle of Mussomeli.

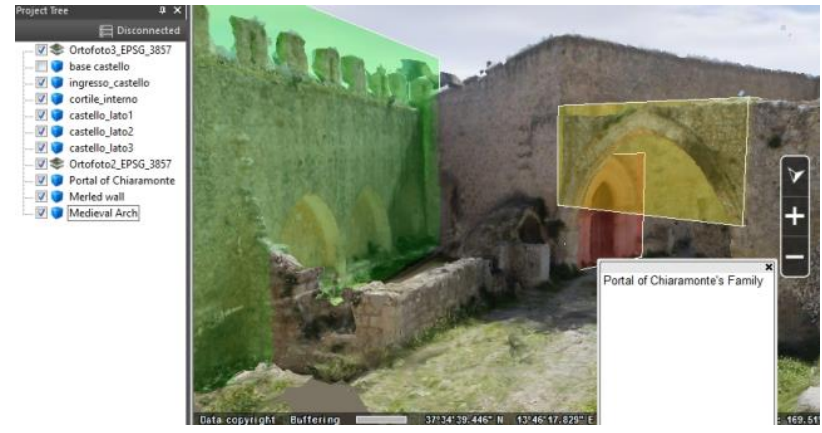

Figure 20. The 3D GIS virtual reconstruction of the main courtyard of the castle of Mussomeli.

\section{RESULTS}

On the light of these studied cases is possible to affirm that every cultural good represents specific features, that require different procedures for each one. On the other hand it's possible to define some main features that characterize the construction of a 3D GIS for $\mathrm{CH}$ cases:
- the necessity of acquiring a strong knowledge about the studied cultural good, and its environment, in order to focus the attention on the geometric and semantic information to insert in the model.

- the choice of the best technologies for the survey acquisition, that depends on the needed LoD, but also on the natural environmental features of the location.

- using the correct simplification solution, in order to lose only useless geometric information, and to create a powerful navigable $3 \mathrm{D}$ model.

- making attention to design the correct structure of the database, dividing correctly the entire environment in macrocategories, categories, microcategories and elements. The kinds of attributes associated to them have to follow the architectural language of that cultural good, and the required LoD.

- the importance of using the same geospatial reference system for every element loaded into the 3D GIS ( ortophotos, 3D models, Shapefiles), in order to avoid reference errors caused by on flight reprojections.

\section{CONCLUSIONS AND OPEN SCENARIOS}

During these last years, 3D modeling technologies have given the possibility of represent virtual and augmented reality applications for archaeological goods (Manferdini et Garagnani., 2011). Furthermore some experimentation have demonstrated the possibility of using BIM technologies for describing archaeological contexts, but only implementing a special inventory of archaeological features (Scianna et al., 2014).

Not far from these conclusions, a similar procedure has to be used for implementing a semantic database into a 3D GIS for archaeological sites. The study about the creation of a standard reference structure for $\mathrm{CH}$ databases is a fundamental operation in order to simplify the development and the diffusion of ICT technologies for archaeological sites. On light of this work, it's possible to affirm that the variation of environmental features for every studied case and the different architectonic language to consider for every cultural good, make the standardization of the database structure a very hard achievement to obtain. Anyway, in the future, next studies could arrive to unify 3D GIS and BIM technologies, in order to create a standardized database structure, where structural elements will be classified according to their architectural constructive system.

\section{REFERENCES}

Dore, C., Murphy, M., 2012. Integration of Historic Building Information Modeling (HBIM) and 3D GIS for Recording and Managing Cultural Heritage Sites. In Virtual Systems and Multimedia (VSMM), 2012, 18th International Conference on.

Fabbri, S., Sauro, F., Santagata, T., Rossi, G., De Waele, J., 2017. High-resolution 3-D mapping using terrestrial laser scanning as a tool for geomorphological and speleogenetical studies in caves: An example from the Lessini mountains (North Italy). Geomorphology, 280, pp.16-29.

Manferdini, A. M., Garagnani, S., 2011. Digital fruition of archaeological finds. The experience at the Archaeological Museum of Bologna. In: DISEGNARECON - TECNOLOGIE PER LA COMUNICAZIONE DEL PATRIMONIO CULTURALE., Vol.4, nº, pp 80-89.

Marques, L., Tenedorio, J.A., Burns, M., Romao, T., Birra, F., Marques, J., Pires, A., 2017. CULTURAL HERITAGE 3D MODELLING AND VISUALIZATION WITHIN AN 
AUGMENTED REALITY ENVIRONMENT, BASED ON GEOGRAPHIC INFORMATION TECHNOLOGIES AND MOBILE PLATFORMS. In ACE: Architecture, City and Environment $=$ Arquitectura, Ciudad y Entorno, 11, pp 117-136.

Pelcer-Vujacic, O., Kovacevic, S., 2016. A GIS Database of Montenegrin Katuns (Kuci Mountain and Durmitor). In Digital Heritage, Progress in Cultural Heritage: Documentation, Preservation, and Protection, 6th International Conference, Euromed 2016, Nicosia, Cyprus, October 31-November 5, 2016, Proceedings, Part II, pp 72-80.

Scianna, A., La Guardia, M., Scaduto, M.L., 2016. Definition of a Workflow for a Web Browsing of 3D Models in Archaeology. In Digital Heritage, Progress in Cultural Heritage: Documentation, Preservation, and Protection , 6th International Conference, Euromed 2016, Nicosia, Cyprus, October 31-November 5, 2016, Proceedings, Part II, pp 41-52.

Scianna, A., La Guardia, M., Scaduto, M.L., 2016. Sharing on Web 3D models of ancient theaters: a methodological workflow. In: The International Archivies of the Phopogrammetry, Remote Sensing and Spatial Information Sciences, vol. XLI-B2, 2016 XXIII ISPRS Congress, 12-19 July 2016, Prague, Czech Republic.

Scianna, A., Susanna, G., Paliaga, S., 2014. Experimental BIM Applications in Archaeology: A Work-Flow. In EuroMed 2014 the International Conference on Cultural Heritage: Documentation, Preservation and Protection, 5 th International Conference, Euromed 2014, Lemessos, Cyprus, 3-8 November, 2014, pp 490-498.

Scianna, A., Villa, B., Ammoscato, A., Corsale, R., 2004. MULTIMEDIA GUIDE IN ARCHAEOLOGICAL SITES BY GIS-GPS TECHNIQUES, POCKETPCS AND POCKET GPSs. In The International Archivies of the Phopogrammetry, Remote Sensing and Spatial Information Sciences, 2004, XX ISPRS Congress, July 2004, Istambul, Turkey.

Siebert, S., Teizer, J., 2014. Mobile 3D mapping for surveying earthwork projects using an Unmanned Aerial Vehicle (UAV) system. Automation in Construction, 41, pp. 1-14.

Tusa S., 2009. Da Mokarta a Monte Polizzo: la transizione dall'età del Bronzo Finale all'età del Ferro. In: atti del V Convegno di Studi del "Progetto Mesogheia", Caltanissetta il 10-11 maggio 2008, pp. 27-52.

Tusa S., Nicoletti F., 2000. L'epilogo sicano nella Sicilia Occidentale: il caso Mokarta - Capanna I. In: Atti delle Terze giornate internazionali di studi sull'area Elima, Gibellina Erice - Contessa Entellina, 23-26 ottobre 1997, pp. 963-984.

Tusa, V., 1991. Segesta. Sellerio Editore. Palermo. 